\title{
NORMAS PARA UNIFORMAR A ORTOGRAFÍA DA NOSA LINGUA
}

DOI: 10.17057/fmfhv.2021.007

Texto inédito, manuscrito. Indicios materiais parecen situar a redacción en Pontevedra, entre os anos 1949 e 1954. O texto e o contido están na base da proposta de Normas prácticas, redactadas en castelán, de 1956. Arquivo familiar.

O documento conservado non ten título. Este foi atribuído polos editores a partir do cabezallo. 

As presentes normas máis que en bases lingüísticas descansan por un lado na necesidá de uniformar a ortografía da nosa lingua nunha obra en que van a colaborar distintos autores dentro da mayor unidá e por outro no afán de facer o máis doada que se poida a leitura desta obra tan importante a xente que non está afeita a ler galego.

Tendo en conta que o castelán é a língua aprendida da mor parte dos presuntos leitores sigo de lonxe as normas desta lingua en contra moitas veces dos meus usos de cotío.

En xeneral foron tomadas da Ortografía Gallega de Couceiro Freijomil, con Apéndices de Abelardo Moralejo, apartádome do que alí se dí en casos contados, e sempre por aforrar estorbo ô que escribe e sobre todo ô que lê.

\section{NORMAS MORFOLÓXICAS}

$1^{\circ}$. As palabras que teñan a misma forma en galego que en castelán non deben variarse basándose nas articulaciós vocálicas indecisas de $a-e, e-i, o-u$, etc. Paréceme vicioso decir «Sacretario» por «secretario», «Médeco» por «médico», «Úneco» por «único», «Páledo» por «pálido».

$2^{\circ}$. Os neoloxismos tomados das linguas crásicas non deben someterse a síncopas, metátesis, diptongaciós, etc. que non señan vivas.

«Rector», «lector», «inspector», etc. penso que se deban escribir así, ben sabido que teñen a pronunciación (propia) da nosa lingua.

$3^{\circ}$. Nos casos de formas dobres, debemos escoller o máis achegado ó latín, non o máis apartado do castelán. Por esta razón penso que se debe escribir «Encontrar» non «alcontrar», «Acender» non «alcender», «Cuestión» non «custión», «Procurar» non «percurar», «Cincuenta» non «cincoenta», «Prolongación» non «prelongación» nin «perlongación». 
40. Nos derivados debemos ter en conta que os sufixos -ACTIONE, -ENTIA, -ITIA e -ITIONE, seña o que queira da sua historia, hoxe dan -ACIÓN, -ENCIA, -ICIA e -ICIÓN. Paréceme por esto un empeño que non val a pena tratar de impoñer formas como "prolongazón», «plantazón», «sabenza», «pacenza» ${ }^{1}$, pola única razón de que haxa dous ou tres casos históricos en que asentar a forma analóxica.

$5^{\circ}$. No emprego de formas históricas caducadas convirá quizaves mellor pecar por carta de menos tendo en conta a obra de que se trata, máis centífica que outra cousa.

$6^{\circ}$. En xeneral, aconsellamos o emprego das formas vivas, montañesas e mariñás dentro de un sentido de dinidá, e lonxe de unha estreita pretensión de purismo.

Das variantes de cada terra penso que se poden manter todas por de pronto e inda alternarse sin merma. Con todo o fonema silbante que ten $c$ e $z$ nas mariñas non debe notarse ortográficamente, por importante que seña, e tamén sería ben non empregar os nobilísimos arcaismos ourensans $i l$, ise, iste, aquil, que non son tan fortes que Curros non os alternase.

Dígase outro tanto das formas analóxicas faguer, frente as etimolóxicas, moito máis estendidas.

\section{NORMAS ORTOGRÁFICAS}

\section{Acentos}

Non usaremos máis que dous acentos: o agudo e o circunfrexo. O primeiro, como en castelán, e ademais con función diacrítica en casos de homónimos como:

á: preposición e artículo.

$d a ́$, dó: verbo e artículo femenino con sustantivo e artículo masculino contracto.

é: verbo ser e conxunción.

sí: adverbio, pronombre e conxunción.

tí nominativo e caso indirecto. Etc.

1 lediza, xustiza (cancelados). 
O circunfrexo debe reducir os artículos contratos: $\hat{a}, \hat{o}, \hat{a} s, \hat{o} s$ con función gramatical. En tódolos demáis casos de contración pode aforrarse.

\section{Representación dos fonemas galegos}

As vocás, inda ben sabido que teñen distinto valor que en castelán, deben representarse, con todo, cos cinco sinos que ten o castelán.

As consonantes da misma maneira, pero tendo en conta que non temos o fonema de $j$ nin precisamos do seu sino, empregando $x$ para o correspondente. Os cultismos en que apareza, como exágona, hexámetro, etc. poden seguir escribíndose con $x$, sobre todo nunha obra como a que se pretende destinada a un lector medio que non terá dificultá na sua interpretación.

No tocante a $y$, somos de parecer que se empregue sempre que teña valor de consonante e por facer mais doada a leitura en palabras como mayo, mayego, cayo, pero non cando semivocal: lei, rei, cheguéi.

Nos casos de semiconsonante «á ti i á min», «a min i á ela» son de parecer que non se escriba $i$, senón $e$. «A ti e á min», «á min e a ela».

Nos casos en que non é máis que a solución eufonica dun hiato máis ou menos craro («Lévame a i-alma») eu diría que non se representase en prosa («lévame a alma»). De facelo, represéntese por $y$, xa que o seu valor é de consonante.

Sobre as formas dudosas España - Hespaña, irmao - hirmao, penso que a primeira debe escribirse con $H$ e a segunda sin ela.

\section{Apóstrofo}

Hai que tender a botar fora este sino que, pretendendo unha escritura fonética, acaba por desfigurar a morfoloxía e ser sempre un estorbo. Pra eso, escribirase a preposición de formando parte sempre dos artículos e dos pronomes de terceira persona [e demostrativo $]^{2}$.

1. Do, da, dos, das.

2. Del, dela, deles, delas.

3. Dun, dunha, dus (duns), dunhas.

4. Deste, dese, desto, deso, etc.

2 Entre parénteses cadradas, un sintagma engadido por outra man [Nota dos editores]. 
Escríbase de sempre separado do demostrativo «aquel» e de calquera outra palabra, verbo, nome, etc., deste xeito: «De ir a Vigo», «de hoxe», etc.

Escríbanse os personales átonos me, che, lle formando sempre unha palabra cos átonos de $3^{\circ}: o$, a, os, as; mo, ma, mos, mas; cho, cha, chos, chas; llo, lla, llos, llas. Pero escríbase separados, e sin perder - e diante os artículos $o, a$, os, as. «Díxome o neno", "dixoche a vella», "dixeronlle os fillos», e da misma maneira, diante calquera outra palabra: «Non me afago», «Díxolle á Lois», «Fálame arreo», etc.

\section{C}

Que, pronome e conxunción, nunca se debe escribir con sinalefa ortográfica, e sempre desta sorte: «O neno que o dixo», «¿Qué home foi ese?», «Xa sei que o sabes», etc.

\section{D}

A preposición con formará unha sola palabra cos artículos desta sorte: $c o, c o a$, cos, coas, cun, cunha, cus (cuns), cunhas, pero non debe xuntarse con outras formas, nin cos demostrativos, con que se xuntaba de, debendo escribirse desta sorte: «con este home», «con esta muller», «con aquel neno», sin apóstrofo nin guiós. En verso pode consentirse a forma $c o$ : «co este», «co ese», etc.

E

A preposición en formará unha sola palabra cos artículos e pronomes con que se xunta, sin necesidá de aseñar este fenómeno con sino ningún: no, na, nos, nas; nel, nela, neles, nelas; neste, nese, naquel; nun, nunha; noutro, etc.

F

O adverbio non e nin en prosa non deberan apocoparse nunca, en prosa centífica sobre todo, escribíndose «non o vin», «non os deixaron», «non houbo», «non hei morrer». En verso ou prosa literaria puidera escribirse, «no o vin», «no os deixaron», «no me fales», etc. Pero non hai por qué facelo á cada día.

As formas pronominás enclíticas causan certos fenómenos fonéticos cando as apoñemos á certas desinencias do verbo, pero non hai por qué señalalas con ningún apostrofo nin guión. Os casos que se presentan son estes. 
- Consonantes epentéticas, orixinarias ou non, que sirven de unión entre os verbos e os pronomes.
a) -n-: haino, leveino, levouno...
b) $-y$-: diyo, farayo, etc.

- Apócopes.

- Nada máis que a de -s- das primeras de plural diante nos. «Librámonos de boas», «imonos de aquí» por «libramosnos», «imosnos».

- Non debemos apocopar - $n$ - d[a] $3^{a}$ de singular nin [de] plural en ningún caso, escribindo sempre: Tenme, tenos, tena, dixéronnos, etc. e non temos por qué separar con guiós â portuguesa a unión do verbo e o pronome.

- Fonemas asimilados.

- As desinencias $s, r$ por asimilación antiga trócanse en $l$ diante os pronomes e artículos $o$, $a$, os, as. Si esto ocurre con verbos epónimos debemos formar unha sola palabra sin ningún sino e escribiremos: dixechelo, escribilas, léchelas, etc.

- Si se da entre verbos e artículos eu penso que non debemos marcar a asimilación e escribiremos «iDixeches o credo?» «iEscribir as cartas!» "¿Leches os versos?», visto que a ortografía ten outra misión que representar a fonética e neste caso interesa máis manter o grupo de artículo e nome, que de outro xeito aparecen separados.

- Si esta asimilación se da entre sustantivos («Diolo arrequente»), adxetivos («entrambolos remos» Curros) e adverbios, mais, mentras (1) e as formas $o, a$, os, as, como son poucos e velando pola pureza das formas, pode seguirse a misma norma, escribindo «Deus o vexa vir» por «Deulo vexa vir».

- Si se da entre pronomes nos, vos, lles e $o$, $a$, os, $a s^{3}$ faremos unha composición sin ningún sino, nolo, volo, llelo, da misma forma que coa preposición por: polo, pola, polos, polas.

- Non faremos o mismo coa preposición tras, visto que é dudoso o seu emprego: «trala casa»e «tras da casa», debendo usar esta última forma.

\footnotetext{
3 Cos pronomes nos vos, lles do pronome $o$, $a$, os, as.
} 
- Víñase indicando con un guión a tendencia fonética de - $n$ final en ben, non, nin, quen, tamén á atraer ô seu grupo fonético os pronomes $o, a$, os, as. Eu penso que non fai falla e que podemos escribir: «ben o vin», «non o vin», «nin o vin», «quen o viu», «tamén o vin».

Resumindo:

- Non empregaremos ningún apóstrofo.

- Non empregaremos ningún guión.

- Empregaremos o circunfrexo. 